\title{
New Product Ideas to Support Macro Breaks in Computer Work
}

\author{
M.C. Dekker* , A.J. van Lochem and J.F.M. Molenbroek \\ Faculty of Industrial Design Engineering, Delft University of Technology, Delft, The Netherlands
}

\begin{abstract}
A healthy work-to-rest ratio during computer work can be an important part of successful preventive workrelated upper limb disorders (WRULD) intervention. Existing break software applications designed to realise such a work-to-rest ratio often possess product features that limit their functionality. Most applications focus on physical relaxation by implementing (micro) breaks into computer work time. Through the emphasis on break time, these applications give the impression that there is no productivity, possibly strengthened by the applications themselves that often visualise the remainder of the break as a slowly decreasing time bar. Moreover, application features such as blocking input devices may counteract cognitive relaxation of computer workers. As imposed physical breaks can be cognitively stressful, especially when deadlines loom, combining physical and cognitive relaxation is a challenge. Actually, research shows that, instead of micro breaks, macro breaks need more attention. It is worthwhile to think of new products for both forms of relaxation within this time span. An idea for a possible product innovation is tested with a small sample and is presented here: a new software application that shows customisable video content during macro breaks.
\end{abstract}

Keywords: Cognitive relaxation, computer work, macro breaks, product innovation, repetitive strain injuries (RSI), workrelated upper extremity musculoskeletal disorders (WRUEMD), work-related upper limb disorders (WRULD), work-to-rest ratio.

\section{INTRODUCTION}

Throughout the last decades, numerous terms were used to indicate discomfort and pain symptoms in the arm, neck and shoulder region, such as Repetitive Strain Injuries (RSI), Cumulative Trauma Disorders (CTD), Occupational Overuse Syndrome (OOS), and Work-Related Upper Extremity Musculoskeletal Disorders (WRUEMD) or Work-Related Upper Limb Disorders (WRULD). More recently, the focus has shifted towards plain designations just indicating the troubled physical area, such as Complaints of Arms, Neck and/or Shoulder (CANS), "neck-shoulder pain", or "armhand pain". The rationale for this shift is that often no specific medical disorder or injury can be diagnosed, and the development of the complaints and the conditions in which they occur can differ strongly. Nevertheless, there is consensus on the nature of the complaints. They are characterised by a feeling of pain, stiffness, tingling, clumsiness, loss of coordination, loss of strength, skin colouring and skin temperature differences [1]. There is also consensus on the multifactorial nature of this syndrome's origin [2]. The most prominent risk factors mentioned in literature are of a physical nature, like repeated movements, static postures, awkward body positions, high forces, and high precision. Besides physical risk factors, psychosocial risk factors such as stress and high job demands, as well as personality traits like overcommitment and perfectionism, have been reported to be associated with these problems [3-

*Address correspondence to this author at the Faculty of Industrial Design Engineering, Delft University of Technology, Delft, The Netherlands; Tel: +31 (0)15 2783028; Fax: +31 (0)15 2787179;

E-mail: m.c.dekker@tudelft.nl
5]. This large variety of symptoms and risk factors suggests that there is not just one mechanism that explains the development of the complaints, but that several mechanisms may act simultaneously [6]. Because the abovementioned terms are either incorrect or incomplete in the sense that they do not cover the syndrome's etiology, the internationally most commonly used and recognised term WRULD will be used in this paper.

One of the most frequently recommended WRULD interventions is the introduction of more rest breaks, to interrupt computer workers' physical and mental loading patterns. According to Blatter et al. [7], improving work-torest ratios, possibly supported by break software, is the most promising preventive measure for WRULD problems related to computer work. These authors base their statement on pathophysiological and etiological plausibility, and conclude that high quality research on the effectiveness of such measures is absent and therefore necessary.

Not only health aspects should be taken into consideration. According to Dul et al. [8], high quality ergonomic systems should optimize both human well-being (including health) and overall system performance (including productivity), and these aspects influence each other in the short and the long term [8].

\section{Legislation, Standards and Recommendations Related to Rest Breaks in Computer Work}

In European countries, the employer has legal responsebilities with regard to work-to-rest ratios in computer work. These are stated in Council Directive 90/270/EEC [9] on the minimum safety and health requirements for work with display 
screen equipment. Article 7 on daily work routine declares: "The employer must plan the worker's activities in such a way that daily work on a display screen is periodically interrupted by breaks or changes of activity reducing the workload at the display screen." There is a relatively wide margin for interpreting this directive. In the United States, the Occupational Safety and Health Act of 1970 requires employers to comply with hazard-specific safety and health standards as issued and enforced by either the Department of Labor's Federal Occupational Safety and Health Administration (OSHA), or an OSHA-approved State Plan. The General Duty Clause in this act requires employers to provide their employees with a workplace free from recognized hazards likely to cause death or serious physical harm. Until now, OSHA has issued no specific required standards for the design of office environments, computer workstations or related users' working patterns. Nevertheless, OSHA aims to inform employers and employees about potential hazards and interventions that employers can use to prevent or reduce the potentially harmful effects of working with computers. OSHA maintains a Web-based 'eTool' [10] on computer workstations in which the following recommendation under 'Micro breaks or rest pauses' is made: "Build short micro pauses into computer use sessions. Frequent short breaks are desirable. Every hour, take a five-minute break from computer tasks. Look away, stretch, get up, or walk. These brief pauses provide time for muscles and tendons to recover." And under 'Task Rotation or Job Enlargement': "If you must perform a variety of tasks, when possible, intersperse them throughout the work day. Minimize long blocks of uninterrupted computer time by doing other non-computer tasks such as photocopying, phone work, cleanup, etc."

Generally, workers have the right to take breaks, but whether or not they are paid for depends on the type of interruption and the terms of their employment contract. We can distinguish between:

1. holidays, typically a number of days off in a row,

2. 'daily rest' and 'weekly rest', the break between finishing one day's work and starting the next day (overnight), and between finishing one week's work and starting the next (weekend),

3. rest breaks, like lunch, coffee, or tea breaks,

4. unplanned interruptions of work, such as a breakdown of equipment, inappropriate design of work, or even fire drills,

5. short rest breaks or pauses.

The first and third types of interruptions are often paid, but do not have to be unless stated in the contract. The second type of break is almost never paid. The fourth type is usually paid work time, and so are the type 5 short rest breaks or pauses taken unconsciously or intentionally by the employee. The duration of this last type of interruptions is in the order of seconds (micro breaks), or minutes (macro breaks), and these are the main focus in the following paragraphs.

\section{LITERATURE REVIEW AND DESIGN OPPORTUNITIES}

\section{Approach}

A literature study was performed on the effectiveness of rest breaks, physical exercises, and existing break software applications. Based on these outcomes, design opportunities were formulated for the subsequent product idea development. Consequently, two product ideas were created reflecting these insights. One of these ideas was subject of a small user test and is presented in more detail.

\section{Effectiveness of Existing Break Software Applications}

Many break software applications, introducing artificial micro and macro breaks into the user's computer work time, were launched with the aim to prevent or reduce musculoskeletal disorders like WRULD. Some applications offer the user possibilities to engage in physical exercises during the breaks. However, the effectiveness of pauses and exercises during computer work has not been defined unambiguously in scientific literature. An examination of the available literature by Mathiassen [11] showed that the effectiveness of more rest breaks and physical variation in jobs with long-lasting low-level loads, or repetitive movements on musculoskeletal disorders is weakly supported by empirical evidence. In a study by Van den Heuvel [12] more specifically, the effects of a software program stimulating (micro and macro) breaks and physical exercises on the recovery from neck and upper limb symptoms among computer workers were evaluated. No effects on self-reported severity and frequency of the symptoms were observed when comparing the pre- and postintervention scores. Additionally, no effects on self-reported sick leave were found. However, subjects retrospectively reported 'perceived recovery' from their complaints more often than a control group without intervention. There seemed to be no additional effect from performing physical exercises during the breaks. Considering the impact of additional breaks on discomfort rather than on complaints, McLean et al. [13] investigated the effect of break-softwareinduced micro breaks (30 seconds at 20 minute intervals, 40 minute intervals, and at participants' own discretion) in the daily routine of female workers performing keying and data entry tasks. They found beneficial effects of micro breaks on subjective discomfort ratings in the neck, the low back, the shoulder, and the forearm/wrist areas, particularly when breaks were taken at 20 minute intervals. Similarly, Galinsky et al. [14] found relatively small but significant reductions in data-entry workers' discomfort when adding macro breaks (four times 5 minutes per day) to their daily programme. Supplementary breaks attenuated accumulation of discomfort during work sessions (most markedly in the back, neck, and dominant shoulder/upper arm regions). No effects of physical exercises (stretching) during breaks on discomfort were observed. Overall mean ratings of discomfort were relatively low, and mean reductions in discomfort produced by the effects of the rest breaks were rather small. Considering these studies, an important open question remains whether these relatively modest effects of rest breaks on discomfort will, in the long term, have positive effects on the prevention or reduction of actual WRULD complaints.

\section{Design Opportunities}

During the second author's master thesis project, two design opportunities - theoretically fruitful directions to 
pursue - were defined based on literature and users' experiences with existing break software.

\section{Design Opportunity 1: Aiming for Cognitive Relaxation}

Mac Lean et al. indicated that if breaks are regimented in computer work, this might result in added stress due to work interruption [13]. In a study by Henning et al., particularly more complicated (less repetitive) VDU operations of computer workers seemed to be susceptible to disruptions of administered rest breaks [15]. Computer workers were found reluctant to comply with scheduled short (3 sec and $3 \mathrm{~min}$ ) rest breaks because of an increased risk of errors or the need to repeat processing steps. Worker self-management of discretionary rest break behaviour (discretional rest breaks with feedback on their rest break behaviour) was proposed in order to improve the integration of the break system with the working tasks. Henning et al. stated that as computermediated work becomes more complex and less repetitive, the importance of integrating short rest breaks with task demands will probably increase since scheduled rest breaks will seriously disrupt these tasks. It can be confirmed that in academic work environments like the Faculty of Industrial Design Engineering at Delft University of Technology [16, 17] or at Wageningen University in the Netherlands [18], the acceptance of existing pause software is rather low. An important reason is that the focus of most break software applications is mainly on physical relaxation while the aforementioned cognitive aspects receive little attention. One example of a cognitively stressful feature is the enforcement of advised breaks on the users, sometimes even by blocking the input devices.

Former studies [19] have shown that computer workers regard unexpectedly long computer response times in combination with computer dependence as an important stress factor. Other adverse features are the displayed remainders of a break, dedicated to physical recovery but creating a cognitive waiting experience. This feedback emphasises temporary inactivity and thus decreased productivity, which induces mental stress especially when a deadline is near; the available time reduces while the amount of work tasks stays the same. The performance of a computer task in combination with exposure to a cognitive stressor can induce (physical) muscular tension [20]. Moreover, there is general agreement on the relationship between extensive muscular tension and the occurrence of WRULD complaints. These connections underline the importance of cognitive relaxation during breaks.

Nevertheless, it is not easy to create cognitive relaxation, for example when users 'just want to finish something'. It is particularly difficult because of human's inability to successfully 'shut down' from mental stress, meaning that these stress levels stay high during breaks [21]. Mental workload and cognitive problems are of a complex nature, more difficult to measure and to provide efficient solutions to, and are more seldom studied or solved in comparison to physical problems in computer-supported work [22]. The realisation of cognitive relaxation during breaks, even though the user has deadlines to meet, presents both possibilities and challenges for future preventive measures.

\section{Design Opportunity 2: Focusing on Macro Breaks}

Regardless of the ongoing debate on possible health benefits of existing break software as discussed in the paragraph 'Effectiveness of existing break software applications', there is some doubt whether these applications are actually able to significantly alter a worker's work-to-rest schedule in itself. Slijper et al. [23] examined the differences in number and timing between natural work-pause patterns of twenty healthy computer users, and their pause patterns when pause regimes, available in a Dutch break software application, were imposed. The participants had computerintensive jobs - an estimated $5.5( \pm 1.1)$ hours per day - in the academic hospital of Rotterdam, the Netherlands. Most of the participants had administrative jobs, were researchers, or had managerial functions. The related time traces were recorded during their computer work, which consisted mainly of text processing, email and Internet tasks. In this study, computer use was referred to as making mouse movements, mouse clicks, mouse wheel use, or keyboard strokes. The obtained time traces in between these events were used to calculate pause distribution.

According to this study by Slijper and colleagues [23], the vast majority $(96 \%)$ of natural pauses were found to be shorter than one second, and only a small number of pauses had long durations. The distribution of pauses was extremely skewed; pauses with twice the duration were approximately twice less likely to occur. In order to examine how the workers' computer use patterns would be altered by the influence of the six least stringent pause regimes of the aforementioned application, a simulation of this software was performed on the recorded time traces. The authors found that the more stringent a regime becomes, the more pauses are administered, and that the majority (89\%) of the administered pauses were micro breaks. On average, 38 micro pauses of five to ten seconds compared to only four macro breaks with durations of five to eight minutes were inserted on a daily basis. Also, the number and timing of pauses with similar time lengths before and after the implementation of the software were compared. In the recorded files, on average $25 \%$ micro breaks were imposed artificially on top of the spontaneously taken micro breaks. With regard to the macro breaks, on average $57 \%$ were inserted additionally to the naturally taken macro breaks. The authors concluded that the number of pauses given on top of the ones that occur naturally is rather small, especially with the micro breaks. With regard to the timing of the administered pauses, the authors found that, specifically for the micro breaks, a large number of spontaneous pauses were taken just before and after the inserted ones. The spontaneous pauses occurred on average within 90 seconds. In contrast, for macro breaks the software administered a pause long before the computer user would take a break spontaneously (on average 53 minutes earlier). An important conclusion by the authors [23] is that the administration of micro pauses by the break software does not lead to a considerable change in the work-pause pattern of computer users. Contrary to that, the administration of macro pauses, even though they comprised only $11 \%$ of the total number of inserted pauses, seems to alter the natural work-pause pattern more substantially. Although current applications focus mostly on implementing micro breaks, these findings 
indicate that new applications should preferably support macro breaks that last from five to eight minutes. By specifically designing for macro breaks, new possibilities arise because of the extended duration, which - in contrast to micro breaks - allows for an increased variety of small activities.

Most longer breaks, with durations of ten minutes and more, such as type 3 (lunch, coffee, or tea breaks) and possibly also 4 (unplanned breaks), are usually taken away from the computer. Even the shorter macro breaks can be an opportunity to get away from the computer completely, by paying a visit to the water cooler, coffee machine, toilet, or meeting with a colleague. However, this article focuses on the support of macro breaks taken in front of the computer. The reasoning for this exploration is that these breaks can be integrated smoothly into the workflow and might create less unintended cognitive stress as compared to the more disruptive (physical) activities away from the computer. Furthermore, it is assumed that the required effort will be low and with that the threshold to take these pauses. Additionally, the effect of physical activity during short breaks should not be overestimated, as indicated in the paragraph 'Effectiveness of existing break software applications'. Finally, this choice for facilitating macro breaks in front of the computer enables the use of new media in WRULD prevention, which is rather new from a designer's perspective.

The authors are aware that additional pauses of longer duration with both cognitive relaxation and some physical exertion, away from the computer (e.g. lunch walks or exercising in a company's fitness room), might be more effective with respect to WRULD prevention. However, since corporate environments might value (short-term) productivity over health, managements' and workers' incentives for such schemes might be lacking.

\section{Product Idea: Watching Video Clips During Macro Breaks}

A product idea, aiming for cognitive relaxation next to physical relaxation during macro breaks taken in front of a computer, is presented here. This idea was designed during the second author's master thesis project. It should be emphasised that this product idea is an illustration of the aforementioned line of thought rather than an elaborated product design.

The idea aims at mental distraction from the actual work tasks by means of personalised entertainment. Besides the aforementioned considerations, an important reason to develop this product idea was to give the user a rewarding experience during the time a break is taken, rather than an unwanted waiting experience.

The idea is an application that shows short video clips (Fig. 1a) during macro breaks. Content on e.g. travel, wildlife, or sports can bring a welcomed cognitive variation. By customising the content to the user's interest, increased cognitive relaxation is expected to occur. A personal profile and ratings (Fig. 1b) could allow for customising - and over time improving - the offered content. Many Internet applications like Spotify, YouTube, and Amazon, which are all online applications that offer traditional relaxing activities like listening to music, watching videos, or shopping, are at present not yet leveraged for WRULD intervention. The embedded functionalities in these applications may further support cognitive relaxation during macro breaks taken at the computer. Breaks providing short video content require no physical input by the user - just watching and physically resting. Nevertheless, these will offer possibilities to unload working muscles (e.g. by taking the hands off mouse and keyboard and putting them in the user's lap) and change the user's working position. Sending a clip to a friend or colleague after watching it - comparable to the standard option in YouTube, for example - can provide for some small talk at the water cooler, possibly improving the work floor socially. Because low social support was identified as a risk factor for elbow/wrist/hand symptoms in a study by Van den Heuvel [5], this application might have accompanying benefits with respect to WRULD prevention.

\section{User Evaluation}

The idea was evaluated in a small user test. The goal of this user test was twofold. Investigating the extent of cognitive relaxation during computer work with videosupported macro breaks, and identifying potential short-term advantages and disadvantages of the product idea.

\section{METHOD}

\section{Participants}

Ten subjects (6 females, 4 males; age between 22-56, mean age 32.3 years) participated in a user study. These participants were academic staff members (5) and students (5) of the Faculty of Industrial Design Engineering at Delft University of Technology. Six participants had WRULD complaints, located in the neck, shoulder, lower arm, upper arm, wrist, hand and / or fingers ( 4 once a year, 2 once a month), and four participants were free of WRULD complaints. The duration of the complaints varied from less than 1 hour to a couple of days. The seriousness of the complaints, expressed in frequency $\mathrm{x}$ duration, varied from 1 to 576 hours per year (mean 115.5 hours a year). Most complaints were not very severe (less than 50 hours a year).

\section{Stimuli and Apparatus}

A limited version of the video clip application was simulated by a Web-based prototype in a local server environment. This prototype offered video footage of African wildlife assuming that this was to most people's interest. The customisation feature based on personal profile and ratings was not included. The prototype was installed on a laptop (MacBook Pro) and positioned on the participant's desk next to his or her own computer. The prototype ran for 3 hours. Most of the time the laptop screen showed a book icon (Fig. 2a), indicating working time laps. After 20 minutes the screen showed the first frame of a nature video and a 'play' button (Fig. 2b), indicating that a video break could be taken. Feedback on the targeted frequency (set every half hour) of taking video macro breaks was displayed by means of a coloured contour around the first video frame (discretional rest breaks with feedback on rest break behaviour in order to improve the integration of the break 
(a)

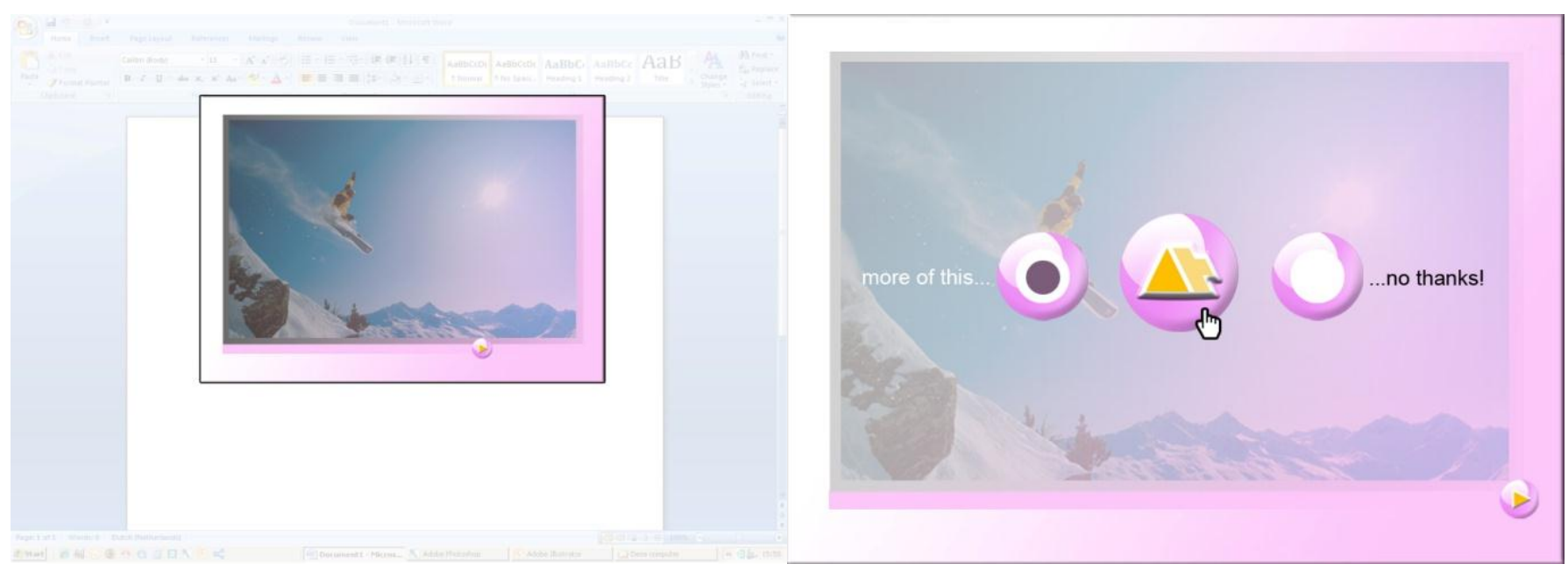

Fig. (1). Two screenshots of the idea: watching (a) and rating (enlarged) afterwards (b).

system with the working tasks, as recommended by Henning et al. [15]). The initial contour was green, after 4.5 minutes the frame turned orange (Fig. 3a), and after 9 minutes the frame turned red (Fig. 3b), and some of these colour transitions were accompanied by modest auditory signals. Subsequently, when not being watched after 10 minutes, the video frame reduced in dimension and moved to the left lower corner of the screen (Fig. 4a), where it could be activated at a later stage or completely omitted. The prototype programme offered a total of 6 video clips with a duration of 5 to 6 minutes with 30 -minute intervals in the 3 hours' running time of the prototype software. A headset (for video sound and auditory signals) was made available for use in shared workspaces.

\section{Procedures}

Prior to the experiment, participants received an instruction and a short demographic survey by email that included questions about age, gender, possible WRULD complaints, and experienced cognitive load (private- and work-related). In the instruction, participants were asked to plan in advance 'mentally demanding and computer-

(a)

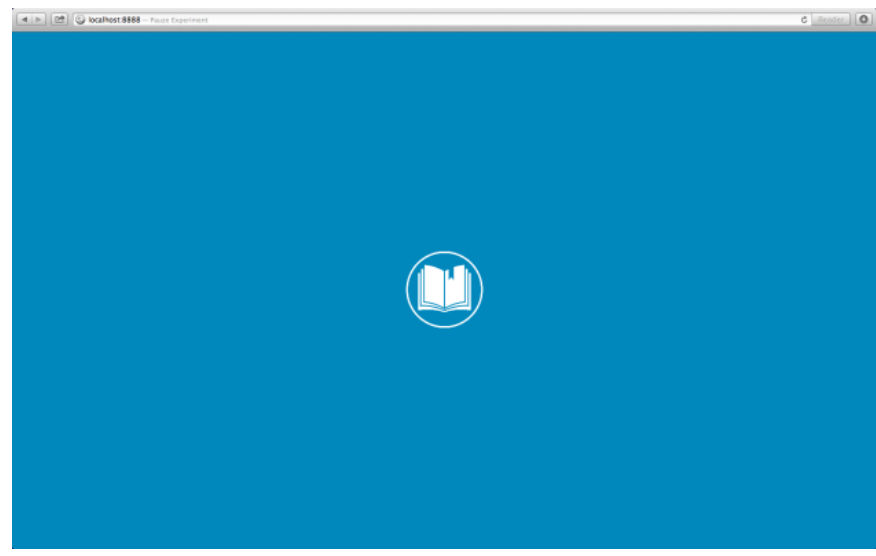

mediated' work activities they were actually engaged in for the 3 hours' time span of the experiment. In order to create a dedicated work attitude, the participants were stimulated to set a goal for what had to be finished within the given time. The location of the experiment was the participant's personal workspace (for academic staff members, Fig. 6a), or a reserved office for personal use (for the participating students, Fig. 6b).

At the start of the experiment, the subjects received a written instruction indicating the aim of the experiment, i.e. to evaluate an alternative way of break-taking during computer work by means of watching short nature videos. Furthermore, it was explained that these would be shown on a laptop next to the participant's personal computer. Participants were asked to cease all computer interactions during the video breaks by removing their hands from the keyboard and the cursor control device (f.i. mouse), to turn their chairs in order to have a perpendicular view on the laptop, to avoid looking at their working screen, to sit back in their chairs, or to move somewhat, and to relax for the duration of the rest break. They were asked to try watching

(b)

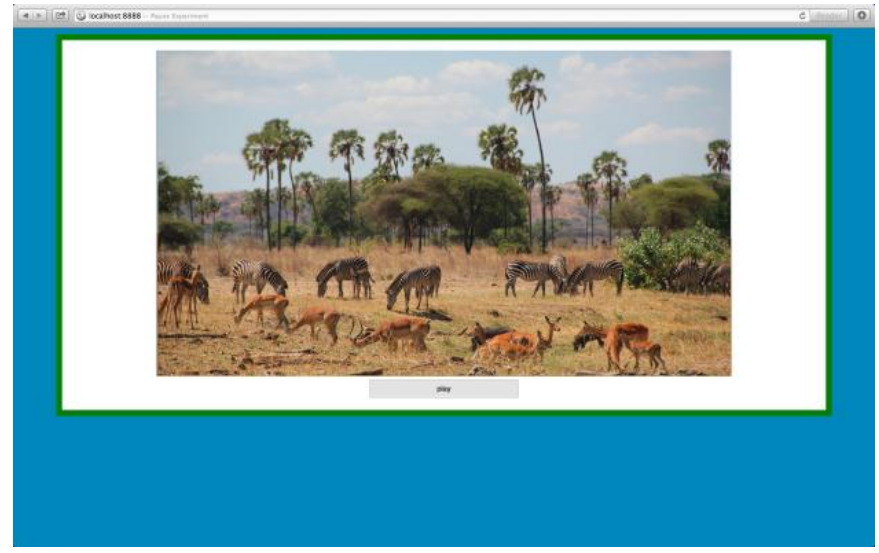

Fig. (2). The application indicating working time laps (a) and the first reminder of a video break to be taken (b). 
(a)

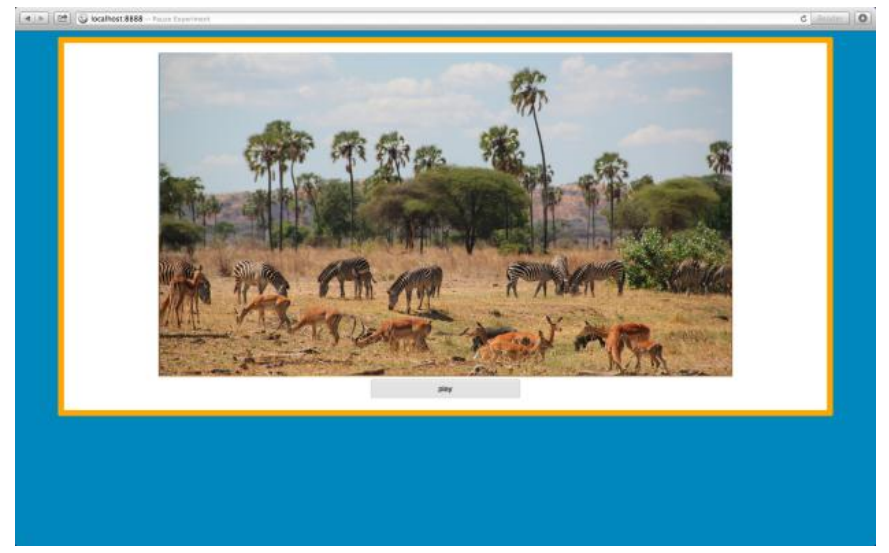

(b)

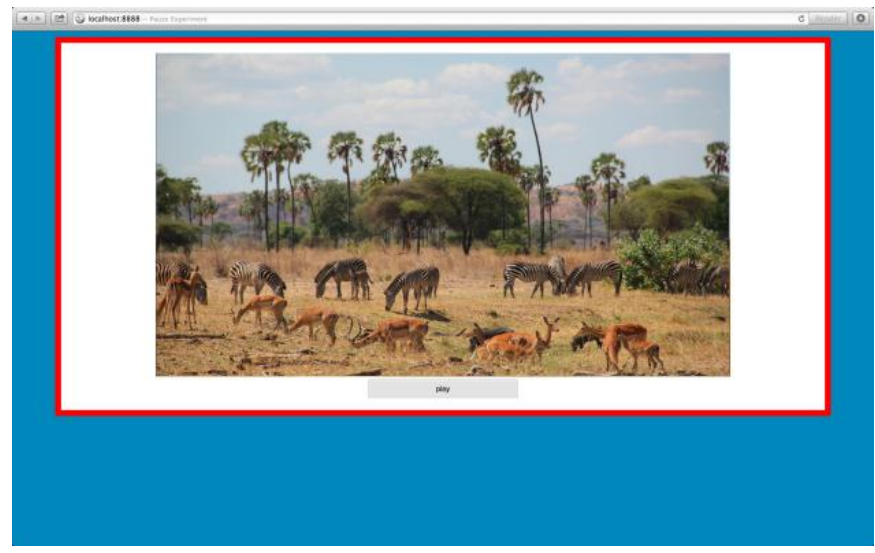

Fig. (3). After 4.5 minutes the frame turns orange (a), and after 9 minutes the frame turns red (b).

all videos (offered every half hour) if possible, but in case of concentrated working periods, watching could be postponed to a more convenient moment or the film could even be skipped. The meaning of the book icon, the contour's colour coding, and the auditory signals was made clear to the subjects as well. Participants were prepared to come across several VAS scales (10-point scale) on their perceived feeling of stress / relaxation displayed on the laptop screen during the programme. Communicating with others or leaving the workspace was allowed, but only for a limited time (5 to 10 minutes).

\section{Measures}

After completion of the 3 hours' working session, participants were interviewed about their perceived cognitive load during watching the videos, during the work spells, and during the 3 hours' experiment as a whole. Furthermore, participants were asked to imagine a working session with similar computer-mediated tasks and in a similar environment as the experimental session they had just finished. The expected differences in their perceived cognitive load and productivity during the 3 hours' experimental session in comparison to 'this working session without video interventions' was questioned. In addition, the revitalising effect during the work spells after the video breaks was examined. The last part of the interview focused on their overall opinion of the video-supported macro break programme including potential short-term advantages and disadvantages of the product idea, and possibilities for product improvement were discussed. Finally, two ideas for video content personalisation were proposed and subjects' opinions towards these ideas were questioned.

Participants' perceived cognitive load was measured by means of a VAS scale (10-point scale) displayed on the laptop screen at the start of the programme, at 2 moments during the work spells (Fig. 4b), and at 2 moments during the video-watching periods (Fig. 5b). The VAS scale representations were all accompanied with the same contour colour coding principle and modest auditory signals as used for the videos. Initially the frame was green, it turned orange after 4.5 minutes, and red after 9 minutes, and disappeared after 10 minutes when ignored by the subject. Both the colour coding and the auditory signals were used to remind the subjects to fill in the VAS scale. This system enabled the participants to integrate this small task into their activities because they had the choice to respond immediately, or to postpone (or omit) the completion of the VAS if they had cognitively demanding work to do or were too much involved in watching the videos.

\section{Analysis}

As the VAS scores (Fig. 7) only indicate the subject's perceived cognitive load at given moments, they were solely used as a trigger for the more general interview questions on perceived cognitive load during the entire work- and watching spells. The subject's answers to the interview questions were written down and grouped per question in a spreadsheet. General tendencies were indicated.

\section{RESULTS}

The participants performed various working tasks during the 3 hours' experimental session. Subjects were writing and reviewing scientific articles and reports, worked on their portfolio and research reports with graphical software, were searching the Web for information, made overviews in spreadsheet software, and used their email programme. In general, subjects were able to work with (great) concentration. Only one participant indicated to have worked with 'moderate' concentration due to distraction by workrelated interactions with colleagues and working on multiple tasks.

Most participants watched the videos quickly (few seconds till few minutes) after appearance of the first reminder pop up. Three out of the 60 videos offered to the 10 participants were completely omitted because of work pressure, multi parallel working tasks, and having just watched a previous video. One video was minimised - not being watched after 10 minutes -, but activated at a later stage. Two participants considered the frequency of video reminder appearance as 'good' and 8 participants preferred a longer time span between the appearance of these reminders, of which 4 participants specified to appreciate a time span of three quarters of an hour above the actual half an hour. Most 
(a)

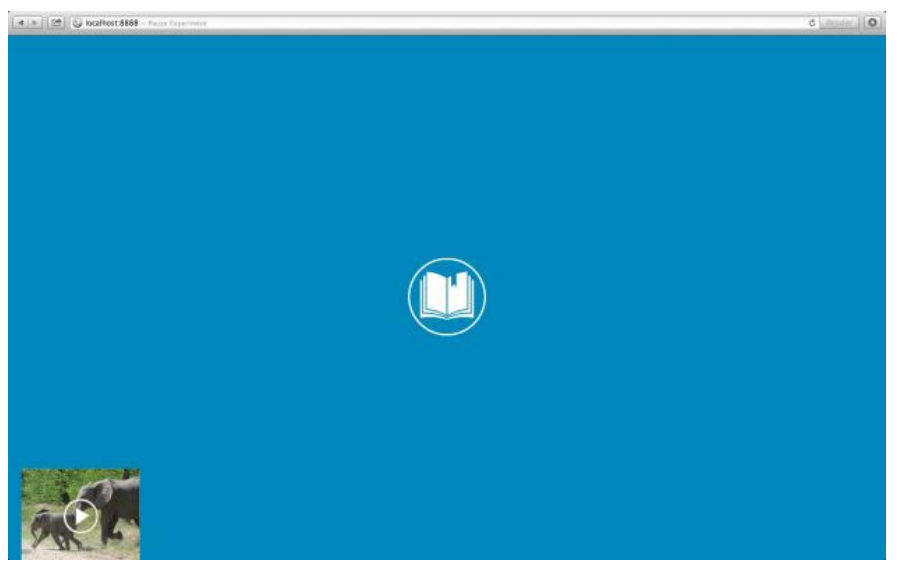

(b)

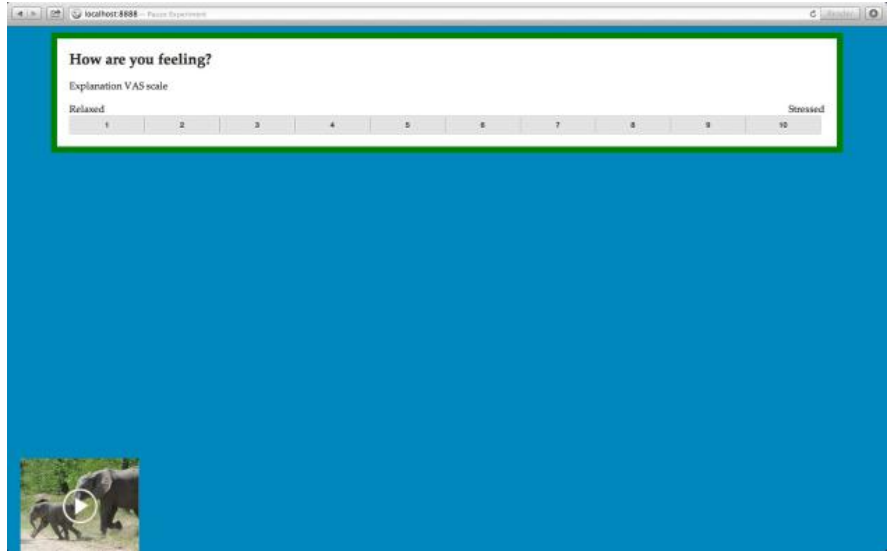

Fig. (4). Continuing working, video being ignored and reduced (a) and VAS reminder in work spell (b).

(a)

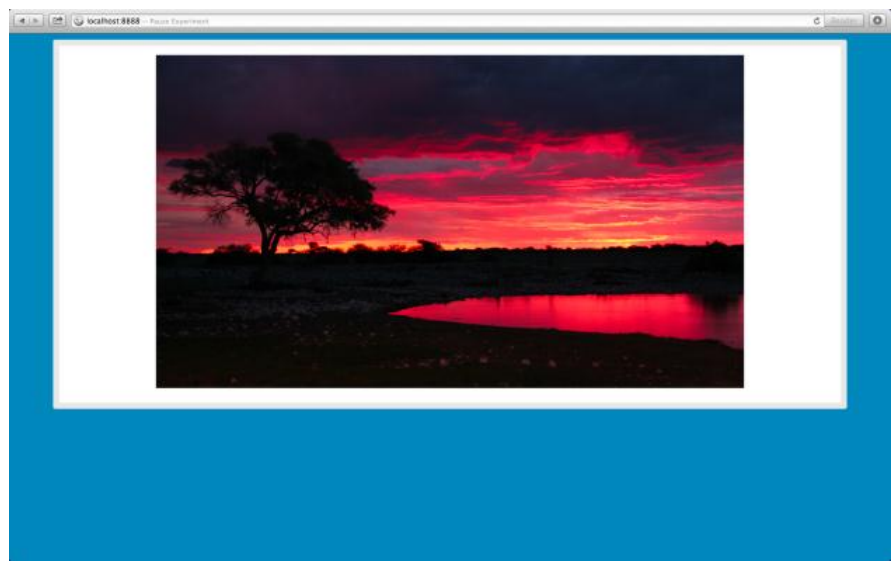

Fig. (5). Watching video (a) and VAS reminder in watching spell (b).

participants found the duration of the videos - 5 till 6 minutes - just good. Three subjects would rather have shorter videos and one subject longer ones.

The majority (7 out of 10 ) of the participants perceived the cognitive load during video watching as 'low' or 'very (b)

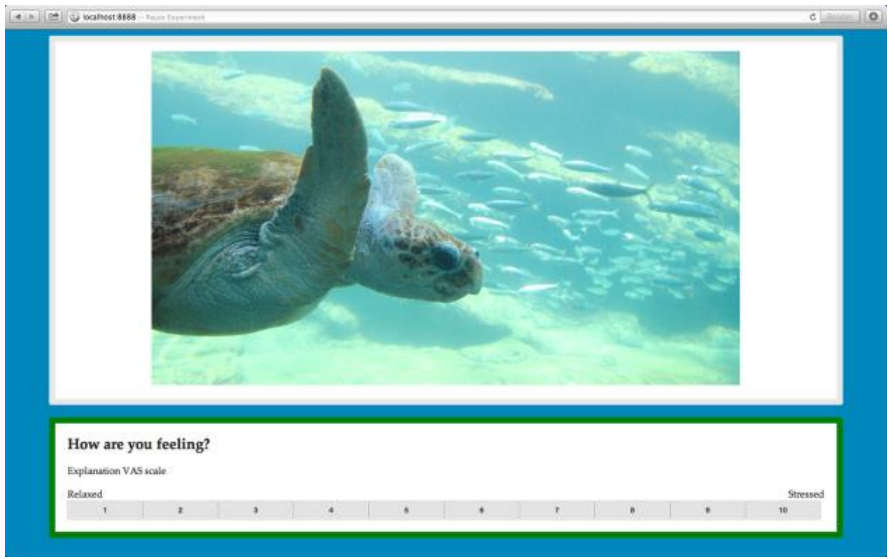

low' (one participant reported a 'holiday feeling'). Two participants mentioned a 'varying' cognitive load caused by work periods with multiple and demanding tasks including verbal interactions with colleagues, alternated with dedicated computer work in which watching the videos could easily be

(a)

(b)

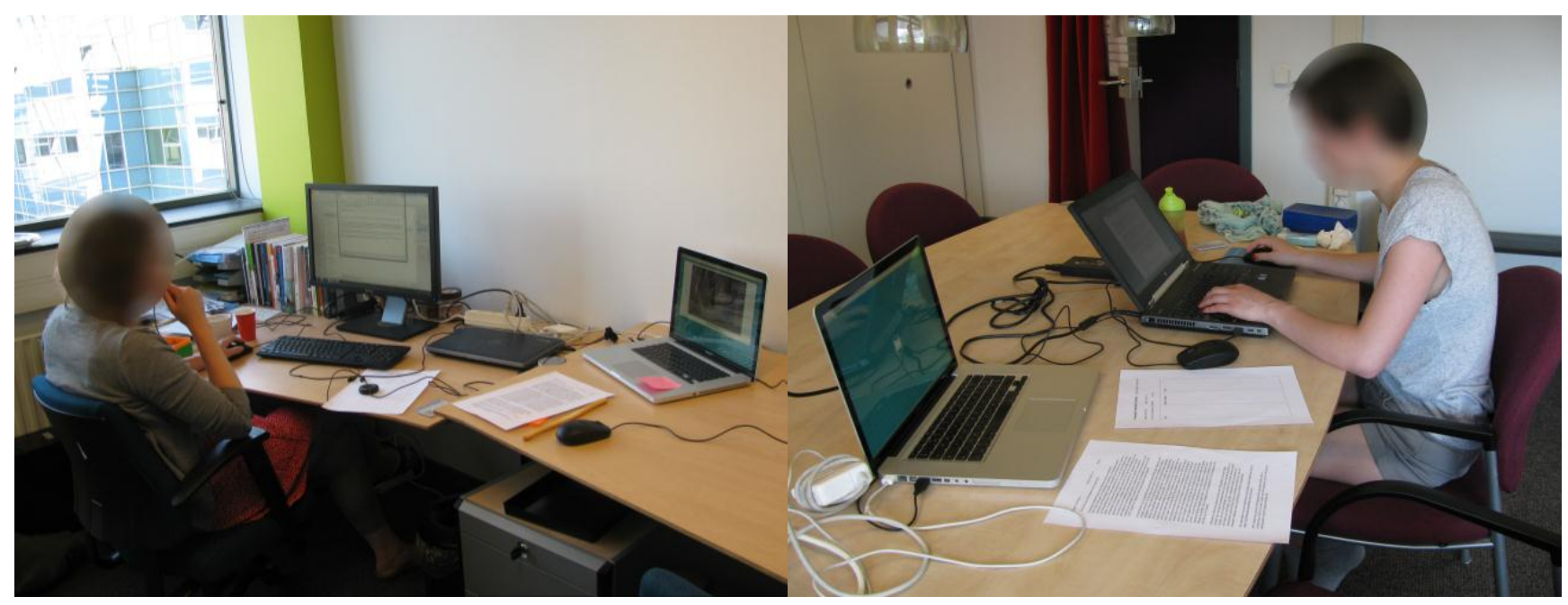

Fig. (6). (a, b) Two participants in their experimental settings. 
integrated. One participant felt distracted and irritated by the videos, because they appeared too often and interrupted the workflow. Four participants spontaneously closed their laptop to also physically set their work aside. The cognitive load during the work spells varied strongly, mainly depending on the work pressure of the tasks at hand. Some participants were under pressure because of deadlines; others had just finished their year of study and were only doing less urgent preparations for the next year. Evaluating the 3 hours' experiment as a whole, most (6 out of 10) participants judged positively ('refreshed feeling after relaxing breaks', 'the videos helped to reduce cognitive load' and 'fixed periods of work and rest made me focus on my work') on their perceived cognitive load, 3 neutral ('First, I had to get used to the programme' and 'First half it went up and second half down'), and 1 negative ('high cognitive load because of irritation by the videos'). Being asked to imagine a working session of similar duration, with similar computer-mediated tasks and in a similar environment, but without video interventions, and to compare their perceived cognitive load of that situation with the 3 hours' experimental session, 6 out of 10 participants expected to experience a 'lower' cognitive load during the experimental session, 2 the 'same' and 2 participants a 'higher' cognitive load. Motivations for an expected 'lower' cognitive load were being able to continue working for a longer time until a large break needed to be taken, a stronger concentration and appreciation of the structured work/rest scheme (being more aware of time). Subjects reported 'same', because on the one hand they felt they lost working time when watching the videos, but on the other hand they valued aspects like being more relaxed or being able to continue working for a longer time before large breaks needed to be taken. The 2 participants who expected a 'higher' cognitive load in the experimental session felt they preferred their own pattern of break-taking and experienced too much distraction from their work by the videos.

Making a similar comparison for the expected productivity between a working session with and without the video interventions, 5 out of 10 participants indicated a 'higher' productivity during the experimental session, 3 the 'same' and 2 a 'lower' productivity. Motivations for an expected 'higher' productivity were the structured work/rest scheme (with rest breaks of defined duration, different from self-initiated breaks that can easily run out of time), avoiding an overloaded mental state, and longer working hours until a large break became necessary. Subjects who reported 'same' found it hard to weigh the advantages and the disadvantages of the programme in terms of productivity. One of these subjects added to expect a higher productivity in the long run if the programme is used on a daily base. One motivation for an expected 'lower' productivity was the fact that the offered video break pattern did not match the preferred individual break scheme, was time consuming, and was therefore counterproductive.

Eight out of 10 participants indicated that they experienced a revitalising effect during the work spells after the video breaks. These participants reported to have experienced reduced mental load after the breaks, to have a new mindset, to be more relaxed, to feel more pleasant, to have less need for a large break, and to be less tired in the head. Two subjects indicated not to have experienced a revitalising effect. One reasoning was the need to mentally pick up work after the video breaks, which cost time and created irritation.

Four participants evaluated the overall video-supported macro break programme as positive. They appreciated the programme as a whole, the created structure, the fact they could work longer hours, the nature theme of the videos, and indicated the programme as comforting, relaxing and rewarding. Another three subjects felt positive about the cognitive relaxation ability of the programme but questioned some physical aspects. They liked the programme to take their mind off things, considered the programme as something really new, and found the videos very interesting. On the other hand they commented that apart from the cognitive relaxation realised by the videos, physical movement, such as walking away from the screen, was still desirable. They felt somewhat bound to the screen and one subject mentioned also the lack of relaxation for the eyes. Two other participants mentioned both positive and negative

\begin{tabular}{|l|c|c|c|c|c|c|c|c|c|c|c|}
\hline & S1 & S2 & S3 & S4 & S5 & S6 & S7 & S8 & s9 & S10 & Mean \\
\hline VAS 1 - start & 4 & 4 & 4 & 2 & 2 & 7 & 7 & 3 & 3 & 4 & 4,00 \\
\hline VAS 2 - work & 5 & 3 & MIS & 4 & 1 & 5 & 8 & 4 & 4 & 5 & 4,33 \\
\hline VAS 3 - work & 3 & 4 & 3 & 6 & 2 & 6 & MIS & 5 & 4 & 4 & 4,11 \\
\hline VAS 4 - movie & 4 & 2 & 2 & 8 & 1 & 7 & 6 & 3 & 2 & 1 & 3,60 \\
\hline VAS 5 - movie & 3 & 3 & 3 & 9 & 1 & 8 & MIS & 1 & 2 & 1 & 3,44 \\
\hline
\end{tabular}

Fig. (7). The VAS scores of the 10 participants, indicating the subjects' perceived cognitive load at given moments. These momentary scores were solely used as a trigger for the more general interview questions on participants' perceived cognitive load during the entire work- and watching spells. MIS = participant did not fill in the VAS scale or skipped the movie in which the VAS scale was shown. 
aspects in regard to the cognitive aspects of the programme. They appreciated the relaxation by the videos. But one of them considered the programme to be again something 'extra' to keep an eye on and the other felt that the breaktaking reminders displayed by the programme and the individually preferred moments of break-taking, were sometimes still not synchronised. One subject found the programme annoying and distracting and was concerned about the social aspect; what would other people think of watching movies in working time?

Looking at possible influences of the existence and severity of WRULD complaints on participants' reported evaluation of the former aspects 'perceived cognitive load during video watching', 'perceived cognitive load during work spells', perceived load during the 3 hours' programme', 'comparison of their perceived cognitive load during video supported working session with similar working session without video interventions', 'comparison of their perceived productivity during video supported working session with similar working session without video interventions', and 'the revitalising effect during the work spells after the video breaks', the results show that both subjects 'without' and 'with' WRULD complaints belong to the group of participants being 'positive' about these aspects of the functioning of the programme. The two subjects who evaluated these aspects mostly negatively, both didn't have WRULD complaints. A similar picture can be drawn when looking at the 'overall opinion of the video-supported macro break programme'.

When being asked for possible improvements of the programme, subjects suggested to make clear to the users of the programme that physical activities are still allowed, or even to let the programme stimulate users to move from time to time like walking away from the computer (3 subjects). Another suggestion was to personify the videos' content according to subjects' personal interest, possibly also workrelated ( 2 subjects). Other proposed improvements were to make the timing and duration of the videos adjustable in advance (2 subjects) based on personal preferences and expected types of work activities, to create indications for the duration of the videos, and to display the videos on a larger screen.

Seven participants sympathised with the proposed idea to be able to choose their video theme based on personal preferences. The common opinion was that the theme should be relaxing and not trigger thinking of daily duties. Two subjects felt 'neutral' towards this idea because on one hand they liked to express their theme preferences but on the other hand they liked to be surprised by the topic (1 subject) or felt that nature was the most relaxing theme amongst all alternatives ( 1 other subject). One subject couldn't imagine any interesting topic for this purpose.

Four participants favoured the last proposed idea of supplying personal video content for the programme, such as footage of holidays, hobby's, their family, etc. They expected to be cheered up by these films or found the idea time saving (no time needed for watching these topics at home). One participant felt 'neutral' towards this idea because personal items can also distract too much or trigger thinking. Five participants stated they wouldn't be interested in this idea because they expected the films to trigger thinking of personal duties, creating extra cognitive load, and preferred more 'restful' topics without a connection with their personal lives.

\section{DISCUSSION}

Ten participants contributed to this user test. Because of this small number, the outcomes contain no statistical significance. Nevertheless, the preliminary outcomes give some relevant insights and leads for further development of the programme.

Six participants experienced WRULD complaints, and four participants were free of these complaints. Most complaints were not very severe. There were both subjects 'with' and 'without' WRULD complaints who felt 'positive' towards the main aspects of the programme. The two subjects who evaluated these aspects mostly negatively, both didn't have WRULD complaints. Because of these small numbers the influence of the WRULD factor on the participants' evaluation of the proposed programme could not be established.

Although the basic idea of the video-supported macro break programme is to remind the users in a gentle, unforced way to take a physical and cognitive break, allowing that users postpone or even omit the video-supported break, the experiment outcomes show that the integration of the video watching in the workflow still needs attention. Because of the experiment set-up in which subjects are being asked to participate and to evaluate the programme, the pressure on the subjects to - strictly - follow the offered break pattern might be higher than in a natural context. The experimental set-up might also be of influence on the participants' frequency and duration of leaving the workspace and moving naturally around, although participants were told this was allowed. The outcomes related to the physical aspects and workflow integration must be seen in this light. However, the authors value the ideas related to the personalisation of the programme in terms of timing of the video reminders, duration of the videos and video content preferences.

Another limitation of the experiment set up was the programme running on a separate laptop. For practical reasons it was impossible to run the programme on the individual working computers. Consequently, it might have been easier to disconnect from the working tasks on the working computer and to concentrate on the videos as compared to the situation in which the working tasks are waiting at the background on the same computer.

An attempt was made to evoke a dedicated working attitude by asking the participants in advance to plan 'mentally demanding and computer-mediated' work activities and to set a goal for what had to be finished within the three hours' time frame. Still some uncertainty remains related to the perceived stress level in the experiment as compared to a real working setting in which deadlines have to be met and the effect on for instance the willingness to take the breaks and the over all evaluation of the programme.

\section{CONCLUSION}

The outcomes of the experiment with the videosupported macro break programme show that computer work 
alternated with watching nature videos of 5-6 minutes results in a low perceived cognitive load during watching the videos, in particular when workers can concentrate on the programme without too much interference from others. The perceived cognitive load during the work spells seems to be strongly depending on the work pressure of the working task at hand. The evaluation of the complete 3 hours' programme (including both breaks and work spells) results mainly in positive judgements on perceived cognitive load. People feel more relaxed, refreshed and more focussed on the working tasks. Compared to a similar working session without videosupported macro breaks, it is expected by the majority of the interviewees that with the proposed programme the perceived cognitive load will be lower; longer hours can be worked before large breaks (type 3 or 2) need to be taken and the offered structure by the regularly offered macro breaks will result in improved concentration. Considering a similar comparison, the most frequently reported expectation is that productivity will be higher with the proposed programme, because of the structured work/rest scheme, the predefined duration of the rest breaks, avoidance of an overloaded mental state and the longer working hours until a large break becomes necessary. Furthermore, the outcomes indicate that a large majority of the interviewees experience a revitalising effect (a new mindset, less tired, more relaxed and feeling pleasant) during the work spells after watching the videos.

Apart from these positive considerations, a small minority is critical towards the previous mentioned aspects; these interviewees experience distraction and irritation when watching the videos, find the frequency of the appearing video reminders too high, experience them as interruptions in their workflow, all resulting in a high perceived cognitive load during watching the videos. They expect to perceive a higher cognitive load with the video-supported programme when compared with a similar working session without the programme because they experience distraction from their actual work by watching the videos and prefer their own pattern of break-taking. Furthermore, they consider the programme to be counterproductive because of the mismatch between their preferred individual break scheme and the offered video break pattern.

The evaluation of the overall video-supported macro break programme shows that the cognitive relaxation ability of the programme (comforting, relaxing, rewarding and taking your mind off things) is predominantly greatly valued, but there are some doubts about the physical aspects. Because of the video-supported programme, people feel somewhat 'bound' to the screen. Besides the cognitive relaxation offered by the programme they need their physical movement like walking away from the computer or doing more extensive physical exercises. Furthermore, the evaluations underline the need to smoothly integrate the offered macro breaks in people's personal workflow, taking into account their type of tasks and personal break-taking preferences in terms of duration of the videos, and timing of the video reminders (and thus the duration of the work spells).

Suggestions for improvement as proposed by the interviewees are: making clear that physical movements are allowed when following the programme, stimulation of physical movement by the programme, and personalisation of the videos' content according to subjects' personal interest. Nature is considered a relaxing and interesting theme. Alternative themes can also be work-related. Personal footage of hobby's, holidays, or family might be less suitable because these can trigger thinking of personal duties and can therefore be counter effective in terms of reducing cognitive load. The preferred duration of the work spells is three quarter of an hour instead of the half an hour as used in the experiment.

\section{GENERAL DISCUSSION}

Only limited evidence supports the conviction that existing break software is beneficial to computer workers' health. This is not opposed to the fact that breaks and physical variation are important. The authors' aim is to evaluate the characteristics of existing break software that might counteract its effectiveness and to explore pathways for new alternatives. A still very conceptual idea is presented in which an attempt has been made to resolve the conflicting situation of physical and mental aspects of relaxation. By focusing on inducing additional macro breaks, it is assumed that the natural working pattern of computer workers can be altered more substantially. Furthermore, attention was paid to a more positive break perception in the sense of experienced rewarding. An evaluation of this idea, being tested only to a limited extent, is shown in the SWOT analysis of Table $\mathbf{1}$ and followed by recommendations for further development.

Whether the idea of video-supported macro breaks would make its way in corporate environments is unknown. Although the authors have confidence in the application's functionality, a too high 'fun factor' could result in adverse associations by management. Moreover, companies' Internet access might be limited, and / or employees' use of the company's email system for the purpose of sending nonwork-related messages might be restricted. The application's compatibility with the working environment of students, for example, is probably higher. WRULD is a problem of serious magnitude amongst this target group, which should receive large attention. At the Faculty of Industrial Design Engineering at Delft University of Technology, for example, $60 \%$ of the students suffer from WRULD complaints in varying degrees of severity [16]. Furthermore, the results of the experiment emphasise that break-taking behaviour is very personal and the integration of the video-supported breaks in the workflow needs extra attention; timing and duration of the video breaks have to be adjustable to a certain degree, depending on working tasks and personal preferences. As well as the content of the video breaks have to be well-tuned to the users' preferences. Nature seems to be a relaxing and broadly appreciated theme. Work-related topics, not too 'heavy', might be appropriate as well as indicated by the experiment. Moreover, because of the screen- and seat bound nature of this idea, the user's mobility - and relaxation of the eyes - needs extra attention. Small physical activities during watching the videos need to be stimulated as well as it has to be emphasised more in general that larger movements as walking and exercising remains indispensible for healthy computer working. 
Table 1. Watching video clips during macro breaks.

\begin{tabular}{|c|c|}
\hline 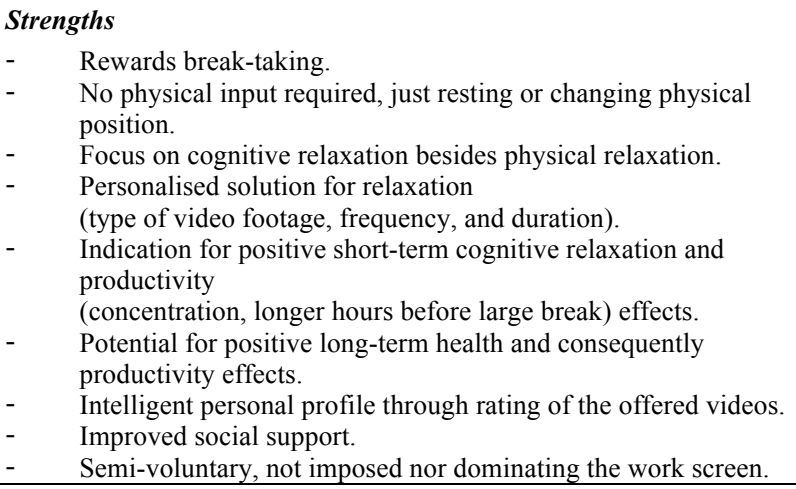 & $\begin{array}{l}\text { Weaknesses } \\
\text { - } \quad \text { Watching the videos takes time. } \\
\text { Integration in the workflow needs attention; adjustable timing and } \\
\text { duration of the videos depending on working tasks and personal } \\
\text { preferences. } \\
\text { Mobility (and relaxation of the eyes) needs extra attention because of } \\
\text { screen/seat bound relaxation; stimulation of small physical activities } \\
\text { during watching videos and walking/exercising at other moments of the } \\
\text { working day. } \\
\text { Content of the video breaks have to be well-tuned to the users' } \\
\text { preferences. } \\
\text { Users' own responsibility for relaxation and health by taking these } \\
\text { voluntary breaks at their own discretion. } \\
\text { Unwillingness to respond to video reminders in case of high work } \\
\text { pressure. }\end{array}$ \\
\hline Opportunities & Threats \\
\hline $\begin{array}{l}\text { - Growing attention of corporate environments for employees' } \\
\text { well-being and health in relation to productivity. } \\
\text { - } \quad \text { Substantial student population. } \\
\text { - } \quad \text { Attention for students' health. }\end{array}$ & $\begin{array}{l}\text { - } \\
\text { funployees lack of acceptance within corporate environments; a too high } \\
\text { management. } \\
\text { - } \quad \begin{array}{l}\text { Ability of employees to mentally pick up work after watching the video } \\
\text { breaks. }\end{array} \\
\text { - } \quad \text { Limited access to Internet for employees. } \\
\text { - } \quad \text { Employees restricted by company's email system usage terms for non- } \\
\text { work-related messages. } \\
\text { - } \\
\text { loconomic downturn, fear to show awareness of health issues (fear of } \\
\text { lobing. }\end{array}$ \\
\hline
\end{tabular}

Another product idea designed during the second author's master thesis project, and building on both aforementioned design opportunities is a dedicated physical input device for Internet tasks. This product idea is intended to reduce mental stress resulting from inactivity during physical break time and to maintain productivity. This idea strives to unite the improvement of work-to-rest ratios with Blatter and colleagues' [7] second most promising measure for WRULD prevention, namely examining the preventive effectiveness of new pointing and input device usage. While traditional computer mice and keyboards are widespread and very useful, they can be a significant source of discomfort due to forearm pronation, planting the base of the wrist on the desktop resulting in contact pressure near the carpal tunnel, wrist extension, ulnar deviation, and extended finger postures [24].

The targeted user groups are computer workers in research, creative, or managerial functions - in contrast with, for example, administrative jobs with more routine activities. This second product idea is an alternative input and pointing device, specifically designed for Internet tasks. These are assumed to be cognitively low demanding and possibly even entertaining. Examples are looking up words in the dictionary, finding pictures to support a presentation, or executing search queries using Google or Wikipedia. Performing such tasks with an alternative input device may lead to cognitive and physical relaxation. Since these moments occur spontaneously, they reduce the need for the more dedicated rest breaks that can be stressful close to deadlines.

A spherical tool (Fig. 8a, b) with a wireless connection to its docking station (Fig. 8c), allows the user to choose work positions and movements, thus adding to mobility and reduction of static muscle tension in front of the computer. The device is preferably controlled from the user's lap (Fig. 9a, b). It realises text input and confirmative mouse actions - left, right, and double clicking - via speech recognition. Speech recognition used to be characterised by long learning curves, but in recent years has become better capable of, for example, listening to specific voice patterns and understanding commands consisting of multiple words.

Internet voice-controlled text input is assumed to be not too disturbing in open-plan offices, since these are often short commands. E-mail functionality, requiring longer text input, is therefore excluded. The navigating mouse actions that are not optimally controlled using speech recognition are realised with gyroscopic technology, as introduced in the gaming industry by Nintendo's Wii remote. The gyroscope translates rotation into X-Y cursor movements on the screen. Because the movements of the cursor on the screen correspond to the rotational direction of the gyroscope, it is expected that navigation is easy to learn. More important than the actual specifications of the device is the fact that this idea allows a rethinking of work tasks and a consideration of whether variation in input for specific tasks could help to define breaks - in the sense of cognitively and physically less demanding or even relaxing episodes - in computer work.

Regarding this second product idea, information has to be obtained related to the Internet behaviour of the targeted computer workers, and differences per job or work task have to be charted. In addition, the physical handling of the spherical tool has to be evaluated with respect to the assumed reduced static muscle tension. Because this product idea is based more on the principle of 'task rotation or job enlargement', as expressed in OSHA's eTool [10] (or 'changes in activity' in the Council Directive 90/270/EEC [9]), rather than on complete disconnection from work, it might be more broadly accepted (corporate employers, employees, students, etc.). On the other hand, acceptation might be limited in shared working environments because of the risk to disturb colleagues by the speech recognition 
(a)

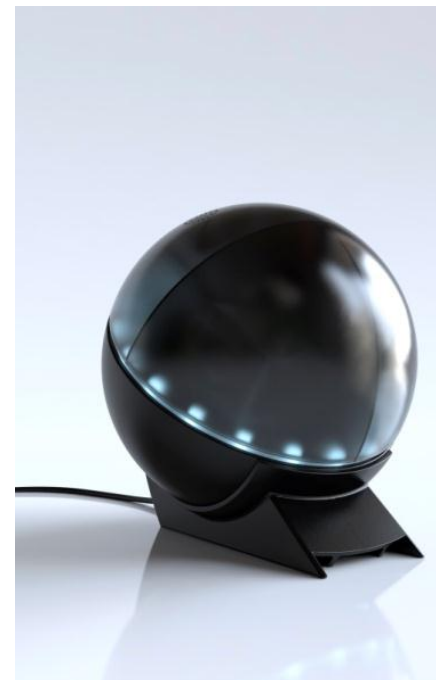

(b)

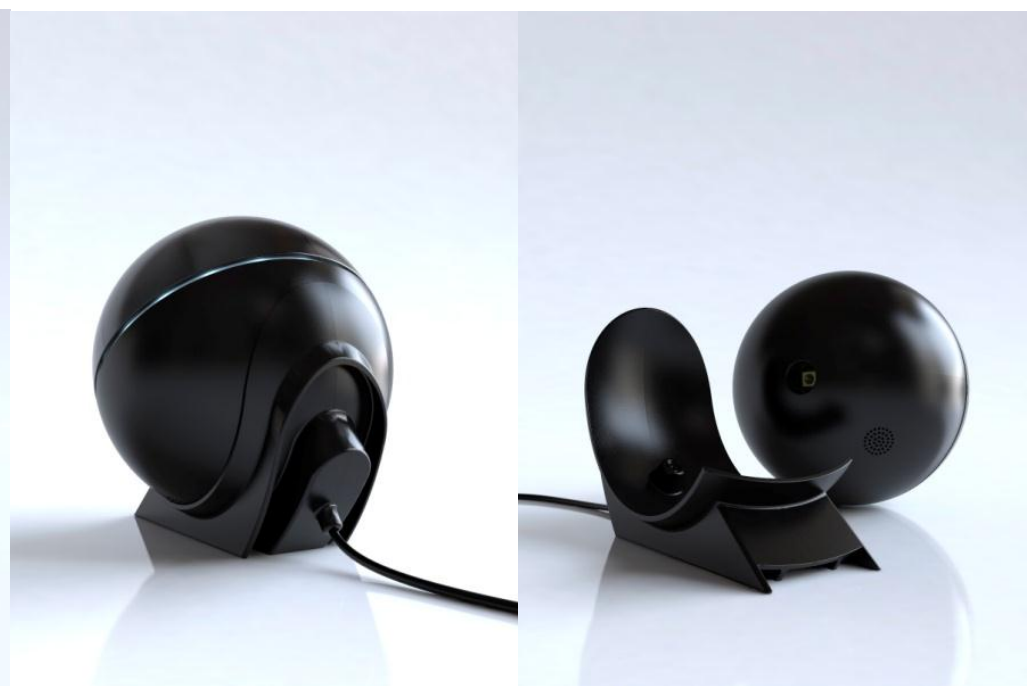

Fig. (8a-c). The input device and its docking station.

(a)

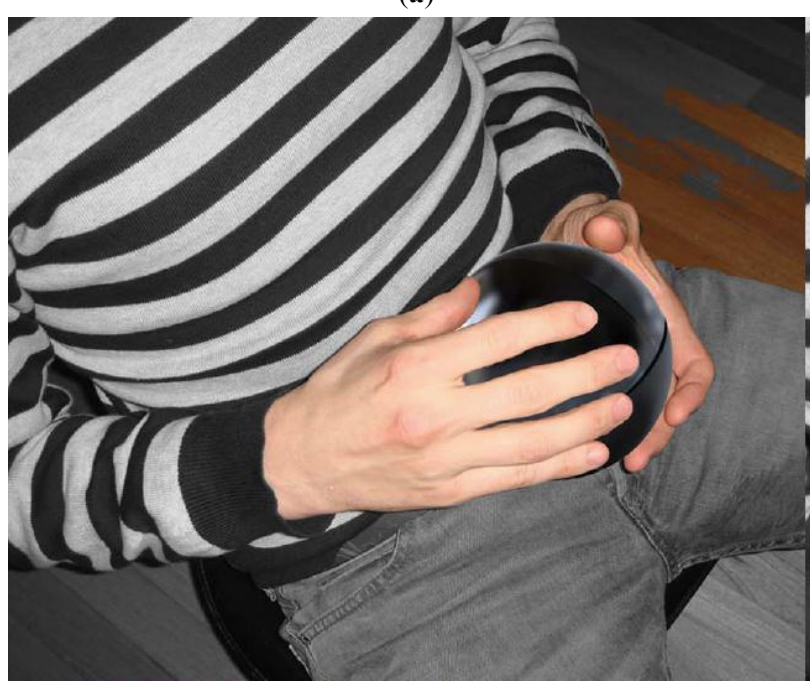

(b)

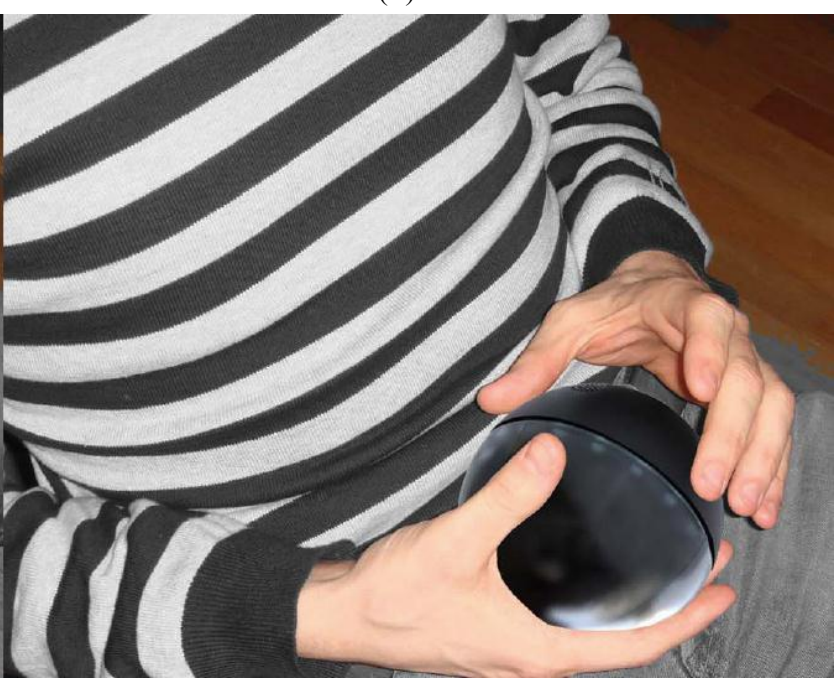

Fig. (9). (a, b) The input device in use.

feature. Apart from these recommendations regarding this second idea, which is not being tested, a SWOT analysis is shown in Table 2.

\section{GENERAL CONCLUSION}

Overall, it seems to be challenging to create a widely supported design for the purpose of combined physical and cognitive relaxation in computer work. Certainly, the effects of both ideas should be thoroughly tested with potential users in order to make well-founded statements about their functioning. Even more importantly, the potential health effects and productivity implications of both ideas have to be investigated for the short and the long term [8]. The recommendations in the aforementioned study on workpause patterns [23] to support the administration of macro breaks are based on the intention to alter users' working behaviours in a positive way, but do not yet give a guarantee for healthy computing nor high productivity. Nevertheless, the very preliminary results of the small-scale user test with the video-supported macro breaks idea indicate that most users perceive this application as cognitively relaxing and productivity improving.

Future research with more elaborated concepts of the two ideas based on the former recommendations should indicate whether these solutions can be characterised as 'comfort improving', 'WRULD complaints preventing', or even 'reducing existing WRULD complaints'. A positive longterm health effect will have a positive influence on the longterm productivity effect, which is a key factor for managements in the decision making process for buying such future products. Although at this stage the two ideas are still very preliminary, they do illustrate new potential for the realisation of health and productivity aspects in computer working by specifically taking into account the cognitive aspects of breaks.

\section{NOTES ON CONTRIBUTORS}

The second author, Sander van Lochem, defined the two design opportunities and designed the product ideas 
Table 2. A dedicated physical input device for Internet tasks.

\begin{tabular}{|c|c|}
\hline Strengths & Weaknesses \\
\hline $\begin{array}{l}\text { - } \begin{array}{l}\text { Potential for cognitive relaxation besides physical relaxation (variety in } \\
\text { physical activity). }\end{array} \\
\text { - } \quad \text { Integrated in the workflow, no time consuming. } \\
\text { - }\end{array}$ & $\begin{array}{l}\text { - } \quad \begin{array}{l}\text { Associated with specific work tasks. Frequency and duration of } \\
\text { breaks dependent on type of job and work tasks. }\end{array} \\
\text { - } \quad \text { Disturbing colleagues in the work environment (noisy). } \\
\text { - } \\
\text { Physical handling of the tool might contribute to physical loading } \\
\text { (muscle tension). } \\
\text { - } \quad \text { Puts some strain on the voice. } \\
\text { Latency }(1 \mathrm{sec}) \text { of speech recognition. }\end{array}$ \\
\hline Opportunities & Threats \\
\hline $\begin{array}{l}\text { - } \quad \text { Health issues (WRULD) related to mouse use. Replacement (partly) of } \\
\text { this } 50 \text {-year-old input device [24]. } \\
\text { - The overall trend of using natural user interfaces (NUIs) and easy to } \\
\text { learn applications }[25,26] \text {. }\end{array}$ & $\begin{array}{l}\text { - } \quad \text { Too much work pressure, unwillingness to change input devices. } \\
\text { Economic downturn, fear to show awareness of health issues (fear } \\
\text { of losing the job). }\end{array}$ \\
\hline
\end{tabular}

presented in this article during his master thesis project [27] at the Faculty of Industrial Design Engineering at Delft University of Technology. The first author, Marijke Dekker, is a university staff member and belonged to the supervisory team of the second author's master thesis project. She is the coordinator of the Working Group on RSI Prevention (WRULD Prevention) at the Faculty of Industrial Design Engineering at Delft University of Technology [16, 17], studies the topic WRULD, undertook an additional literature review for this article, and performed the user tests with the Web-based prototype. The third author, Johan Molenbroek, is also a university staff member at the Faculty of Industrial Design Engineering at Delft University of Technology and supported the writing of this article.

\section{CONFLICT OF INTEREST}

The authors confirm that this article content has no conflict of interest.

\section{ACKNOWLEDGEMENTS}

The authors would like to express their appreciation to Henri Christiaans for participating in the supervising team of Sander van Lochem's master thesis project at the Faculty of Industrial Design Engineering at Delft University of Technology - being the foundation of this paper. We would like to thank Emiel den Exter, who made the Web-based prototype of the limited version of the video clip application as a student assistant at the Faculty of Industrial Design Engineering at Delft. And we are grateful for the African wildlife pictures taken by Wouter Molenbroek as used in the explanatory images of the video application (Fig. 2a up to and including Fig. 5b). Due to copyrights, these nature pictures replace the stills of the original wildlife video footage, conveying similar impressions.

\section{REFERENCES}

[1] Yassi A. Repetitive strain injuries. Lancet 1997; 349: 943-47.

[2] Bongers PM, Ijmker S, Van den Heuvel SG, Blatter BM. Epidemiology of work related neck and upper limb problems: Psychosocial and personal risk factors (part I) and effective interventions from a bio behavioural perspective (part II). J Occup Rehabil 2006; 16(3): 279-302.
Bongers PM. Are psychosocial factors, risk factors for symptoms and signs of the shoulder, elbow, or hand/wrist? A review of the epidemiological literature. Am J Ind Med 2002; 41 (5): 315-42.

[4] Van Eijsden-Besseling MDF, Peeters FPML, Reijnen JA, de Bie RA. Perfectionism and coping strategies as risk factors for the development of non-specific work-related upper limb disorders (WRULD). Occup Med 2004; 50 (2): 122-7.

[5] Van den Heuvel SG. Work-related neck and upper limb symptoms [Unpublished doctoral dissertation]. Vrije Universiteit Amsterdam 2006.

[6] Huysmans MA. From precision demands to neck and upper extremity pain [Unpublished doctoral dissertation]. Institute for Research in Extramural Medicine (EMGO Institute): Vrije Universiteit Amsterdam 2008.

[7] Blatter BM, Bongers PM, Van Dieën JH, et al. RSI-maatregelen: preventie, behandeling en reïntegratie. Programmeringsstudie in opdracht van de ministeries van Sociale Zaken en Werkgelegenheid en van Volksgezondheid, Welzijn en Sport [RSI-measures: prevention, therapeutic treatment and rehabilitation. Study commissioned by the Dutch Ministry of Social Affairs and Labour and the Dutch Ministry of Health, Welfare and Sport]. Doetinchem, The Netherlands: Reed Business Information 2004.

[8] Dul J, Bruder R, Buckle P, et al. A strategy for human factors/ergonomics: developing the discipline and profession. Ergonomics 2012; 55 (4): 377-95

[9] European communities. Council directive 90/270/EEC of 29 May 1990 on the minimum safety and health requirements for work with display screen equipment. Official Journal of the European Communities, L156, 14-18. Available from: http://eurlex.europa.eu/LexUriServ/LexUriServ.do?uri=CELEX:31990L027 0:en:HTML [Accessed 19 July 2012].

[10] U.S. Department of Labor. Occupational Safety \& Health Administration. eTool on computer workstations. Available from: http://www.osha.gov/SLTC/etools/computerworkstations/more.htm 1 [Accessed 19 July 2012].

[11] Mathiassen SE. Diversity and variation in biomechanical exposure: What is it, and why would we like to know? Appl Ergon 2006; 37 (4): 419-27.

[12] Van den Heuvel SG, de Looze MP, Hildebrandt VH, Thé KH Effects of software programs stimulating regular breaks and exercises on work-related neck and upper-limb disorders. Scand J Work Environ Health 2003; 29 (2): 106-16.

[13] McLean L, Tingley M, Scott RN, Rickards J. Computer terminal work and the benefit of microbreaks. Appl Ergon 2001; 32 (3): 225-37.

[14] Galinsky TL, Swanson N, Sauter S, Dunkin R, Hurrell J, Schleifer L. Supplementary breaks and stretching exercises for data entry operators: a follow-up field study. Am J Ind Med 2007; 50 (7): 519-27.

[15] Henning RA, Jacques P, Kissel GV, Sullivan AB, Alteras-Webb SM. Frequent short rest breaks from computer work: effects on productivity and well being at two field sites. Ergonomics 1997; 40 (1): 78-91.

[16] Dekker MC, Festen-Hoff K. Prevention of repetitive strain injuries (RSI) at Delft University of Technology. In: De Waard D, Brookhuis KA, Van Egmond R, Boersema T, Eds. Human Factors 
in Design, Safety, and Management. Maastricht, The Netherlands: Shaker 2005; p. 139-52.

[17] Dekker MC. Faculty of Industrial Design Engineering at Delft University of Technology. Scientific website about Repetitive Strain Injury (RSI). How to prevent RSI; Results from (the faculty's) RSI research; A guide of action if one experiences RSI symptoms. For TU Delft students, employees and other interested researchers. Available from: www.io.tudelft.nl/rsi [Accessed 03 May 2013].

[18] Wageningen University. Students are avoiding 'irritating' pause software. Available from: http://resource.wur.nl/en/student/detail/st udents_are_avoiding_irritating_workpace/ [Accessed 03 May 2013].

[19] Åborg C, Billing A. Health aspects of 'the Paperless Office'evaluations of the introduction of electronic document handling systems. Behav Inform Technol 2003; 22 (6): 389-96.

[20] Van Galen GP, Müller MLTM, Meulenbroek RGJ, Van Gemmert AWA. Forearm EMG response activity during motor performance in individuals prone to increased stress reactivity. Am J Ind Med 2002; 41 (5): 406-19.
[21] Lundberg U. Psychophysiology of work: stress, gender, endocrine response, and work-related upper extremity disorders. Am J Ind Med 2002; 41 (5): 383-92.

[22] Sandblad B, Gulliksen J, Åborg C, et al. Work environment and computer systems development. Behav Inform Technol 2003; 22 (6): 375-87.

[23] Slijper HP, Richter JM, Smeets JBJ, Frens MA. The effects of pause software on the temporal characteristics of computer use. Ergonomics 2007; 50 (2): 178-91

[24] Odell D, Johnson P. Evaluation of a mouse designed to improve posture and comfort, paper presented at the 2007 Symposium on Work With Computer Systems (WWCS 2007), 115. Retrieved July 29, 2013, from http://ode11.com

[25] Dernoncourt F. Replacing the computer mouse. Massachusetts Institute of Technology 2013.

[26] http://en.wikipedia.org/wiki/Natural user interface [Accessed 21 May 2013].

[27] Van Lochem AJ. Using modern technologies and trends in new RSI intervention strategies [Unpublished master's thesis]. Delft University of Technology 2008

(C) Dekker et al.; Licensee Bentham Open.

This is an open access article licensed under the terms of the Creative Commons Attribution Non-Commercial License (http://creativecommons.org/licenses/by$\mathrm{nc} / 3.0 /$ ) which permits unrestricted, non-commercial use, distribution and reproduction in any medium, provided the work is properly cited. 